Check for updates

The BMJ

fgodlee@bmj.com Follow Fiona on Twitter @fgodlee

Cite this as: BMJ2020;370:m3258

http://dx.doi.org/10.1136/bmj.m3258

Published: 20 August 2020

\section{Covid-19: Less haste, more safety}

\section{Fiona Godlee editor in chief}

Few can doubt that we need a vaccine for covid-19 as soon as possible, and great strides are being made, including in our understanding of the immunology of SARS-CoV-2. ${ }^{1}$ But what damage may result from the race to create one? The World Health Organization has produced guidance on minimum characteristics for a vaccine, including 50\% efficacy, temperature stability, potential for rapid scale-up, and proper evaluation against comparators. But, writes Els Torreele, these basic requirements are being rapidly eroded by the prevailing view that anything is better than nothing. ${ }^{2}$ So instead we are heading for vaccines that reduce severity of illness rather than protect against infection, provide only short lived immunity, and will at best have been trialled by the manufacturer against placebo. As well as damaging public confidence and wasting global resources by distributing a poorly effective vaccine, this could change what we understand a vaccine to be. Instead of long term, effective disease prevention it could become a suboptimal chronic treatment. This would be good for business but bad for global public health.

"Vaccine nationalism” is also a concern, says Daniel Altmann. ${ }^{3}$ Russia's approval of its vaccine, based on a small unpublished phase 2 study in 38 volunteers, suggests we are already in the grip of a cold war style arms race, he says. Side stepping the need for a large phase 3 trial is like "entering a marathon, running the first few metres, then unilaterally crowning yourself the winner as all the others run ahead."

Proper testing for patient safety is at the heart of a new drive for ergonomic design of medical equipment, writes Jane Feinman. ${ }^{4}$ Ergonomics, or human factors, means reducing the likelihood of human error, and is especially important for high risk equipment being used in stressful and unfamiliar situations such as those experienced by staff at the height of the pandemic. Perhaps covid-19 will inspire a widespread passion for good design, evaluation, and procurement, so that staff are no longer scapegoats for mistakes caused by poorly purchased equipment.

Are we in the UK ready for winter? John Middleton predicts a perfect storm of resurgent covid-19, flu, a backlog of untreated long term conditions, excess cold related mortality, and the effects of economic collapse and a possible no deal Brexit. ${ }^{5}$ To be ready, he concludes, we will need all the public health interventions that weren't properly implemented from the start: surveillance, test and trace, physical distancing, quarantine and isolation, and protection of staff and vulnerable groups. Now is the time to prepare, but for this the UK needs a strategy rather than a continued round of knee jerk reactions to events. ${ }^{6}$

Sewell HF, Agius RM, Stewart M, Kendrick D. Cellular immune responses to covid-19. BM/2020;370:m3018. doi: 10.1136/bmj.m3018 pmid: 32737031 Torreele E. The rush to create a covid-19 vaccine may do more harm than good. BMJ2020;370:m3209doi: 10.1136/bmj.m3209.

Altmann D. Finding the best covid-19 vaccine should not be a race. 14 August 2020. https://blogs.bmj.com/bmj/2020/08/14/finding-the-best-covid-19-vaccineshould-not-be-a-race.

Feinman J. How covid-19 has highlighted the importance of design as well as price in the NHS supply chain. BMJ2020;370:m3192.

Middleton J. Winter is coming: is the UK prepared? 14 August 2020. https://blogs.bmj.com/bmi/2020/08/14/john-middleton-winter-is-coming-is-the-uk-prepared

Adebowale V, Alderson D, Burn W, et al. Covid-19: Call for a rapid forward looking review of the UK's preparedness for a second wave-an open letter to the leaders of all UK political parties. BMJ 2020;369:m2514. doi: 10.1136/bmj.m2514 pmid: 32576551 